\title{
Clinical Observation Subcategory
}

National Cancer Institute

\section{Source}

National Cancer Institute. Clinical Observation Subcategory. NCI Thesaurus. Code C102740.

A subdivision of clinical observational data. 